\title{
AN OVERVIEW OF THE FERTILITY TRENDS IN ONTARIO AND QUEBEC
}

\author{
N. Baskara Rao \\ Institute for Economic and Social Change, Bangalore, India
}

\begin{abstract}
Résumé-Des taux relatifs de fécondité en Ontario et à Québec avaient changé d'une façon remarquable pendant les 40 ans depuis 1926. Pendant la période 1939-60, l'Ontario témoigna une augmentation considérable en fécondité, alors qu’à Québec le "baby boom" ne connut qu'une courte durée et l'augmentation d'après-guerre en fécondité fut très insignifiante. Le taux total de fécondité de Québec fut 58 pour cent plus élevé que celui de l'Ontario en 1926; cependant, en 1965 le taux fut 4 pour cent plus bas à Québec. Autrement qu'en Ontario, l'augmentation en fécondité maritale fut très négligeable à Québec. Comparée à la cohorte de la période 1907-11, la dimension de la famille (à l'âge de 44 ans) de la cohorte de 1922-26 était plus grande de 30 pour cent en Ontario et de 5 pour cent à Québec. : La tendence vers un âge plus jeune à la grossesse parmi les cohortes récentes en comparaison de celles d'autrefois, fut plus marquante à Québec qu'en Ontario.
\end{abstract}

Abstract-Relative levels of fertility in Ontario and Quebec changed remarkably during the 40 years since 1926. During 1939-60, Ontario had a substantial increase in fertility, while in Quebec the "baby boom" was only for a short period and the post-war increase in fertility was quite insignificant. The total fertility rate of Quebec was 58 per cent higher than that of Ontario in 1926; however, in 1965, the rate was 4 per cent lower in Quebec. Unlike in Ontario, the increase in marital fertility was quite negligible in Quebec. Compared to the 190711 cohort, the family size (at age 44) of the 1922-26 cohort was larger by 30 per cent in Ontario and 5 per cent in Quebec. The tendency towards a younger age at childbearing among the later cohorts compared to the earlier, was more prominent in Quebec than in Ontario.

Ontario and Quebec, two provinces in Canada, differ with respect to some socioeconomic factors. About $88 \%$ of the population (1961) are Roman Catholics in Quebec and $30 \%$ in Ontario. The proportion of Protestants is much higher in Ontario. The Frenchspeaking population is $81 \%$ in Quebec and $10 \%$ in Ontario. During 1926-65, Quebec's per capita personal real income was on an average, $23 \%$ to $33 \%$ lower than that of Ontario. Since fertility is known to respond to differences in religion, ethnicity and levels of income, it would be of interest to compare the fertility trends and the age patterns of childbearing in these two provinces.

\section{Trends in Period Fertility Rates}

During 1926-39 TFR (Total Fertility Rate) generally declined in both Ontario and Quebec. However, the decline was relatively faster and more consistent in Quebec. During 1939-60, approximately the period of the "baby boom," TFR increased in. both these provinces. However, substantial increase in Quebec's fertility took place only during the short period of 1939-47. While the post-war increase in fertility was quite prominent in Ontario, it was almost negligible in Quebec. Between 1939 and 1960, TFR in Ontario rose by about $72 \%$, while in Quebec, the extent of increase was only 17\%. During 1960-65, though TFR declined in both the provinces, the process was faster in Quebec. As a result of the differential rates of change in fertility over time, the relative levels of fertility in Ontario and Quebec changed remarkably. In 1926, the TFR of Quebec was $58 \%$ higher than that of Ontario. However, this excess fertility was wiped out in 1960, and in 1965, it was $4 \%$ less.

Since annual data are available only for a short period, it is difficult to examine in 
TABLE 1: TOTAL FERTILITY RATES (per 1000 women aged 15-49), 1926-65

\begin{tabular}{llllll}
\hline Year & \multicolumn{2}{c}{ TFR } & Year & \multicolumn{2}{c}{$\begin{array}{c}\text { Average change } \\
\text { per annum in TFR }\end{array}$} \\
& Ontario & Quebec & & Ontario & Quebec \\
\hline 1926 & 2730 & 4307 & & & \\
1930 & 2748 & 4059 & $1926-30$ & 0.2 & -1.5 \\
1935 & 2276 & 3369 & $1930-35$ & -3.7 & -3.6 \\
1940 & 2316 & 3287 & $1935-40$ & 0.4 & -0.5 \\
1945 & 2469 & 3666 & $1940-45$ & 1.3 & 2.2 \\
1950 & 3111 & 3812 & $1945-50$ & 5.1 & 0.8 \\
1955 & 3732 & 3904 & $1950-55$ & 3.7 & 0.5 \\
1960 & 3793 & 3764 & $1955-60$ & 0.3 & -0.7 \\
1965 & 3125 & 2996 & $1960-65$ & -3.7 & -4.4 \\
\hline
\end{tabular}

Source: Statistics Canada, Vital Statistics reports for relevant years.

detail the trends in marital fertility rates. However, changes over a decade or a quinquennium could be compared. In Ontario, ASMFR (Age Specific Marital Fertility Rate) declined in all the age groups, $15-19$ through $40-44$, in the 1931-44 period. During 1941-51 and 1951-56, all the groups, particularly the 25-39 during 1941-51 and the 15-24 during 1951-56, contributed to the increase in marital fertility. With only two exceptions, ASMFR declined in all the age groups during 1961-65. In Quebec, on the other hand, increase in marital fertility was more an exception than a rule. Instances of a rise in marital fertility could be observed only in the 15-19 age group during 1941-51 and in the 15-29 group for the following five-year period. In both cases, the rates of increase were far less than in Ontario. Further in Quebec during 1941-51, ASFR (Age Specific Fertility Rate) increased in the 1534 age range while ASMFR declined in the 20-34 group. In other words, whatever increase in fertility occurred in Quebec could be attributed more to a greater proportion of population getting married and having children than to any significant increase in marital fertility.

In 1931, except in the 15-19 age group, Quebec's ASFR was higher. In 1965, fertility rates in the 15-29 group there were lower. In the older groups (30-44), though fertility was still higher, the difference had narrowed considerably during 1931-65. In 1931 and 1965 ASMFR in each age group was higher, except in the 15-19 group in 1965. However, the difference, as in the case of ASFR, was much less in 1965 than in 1931. Due to the lower proportion of the married, excess fertility in that province was more evident in ASMFR than in ASFR.

It is known that changes in period fertility rates are due to changes in completed family 
size and/or changes in the age pattern of childbearing. Let us examine the trends in these two components.

\section{Cohort Fertility Rates}

By reconstructing the annual age specific fertility rates from 1926, to 1966 we can get cohort fertility rates and these rates can be compared, assuming no mortality or migration.

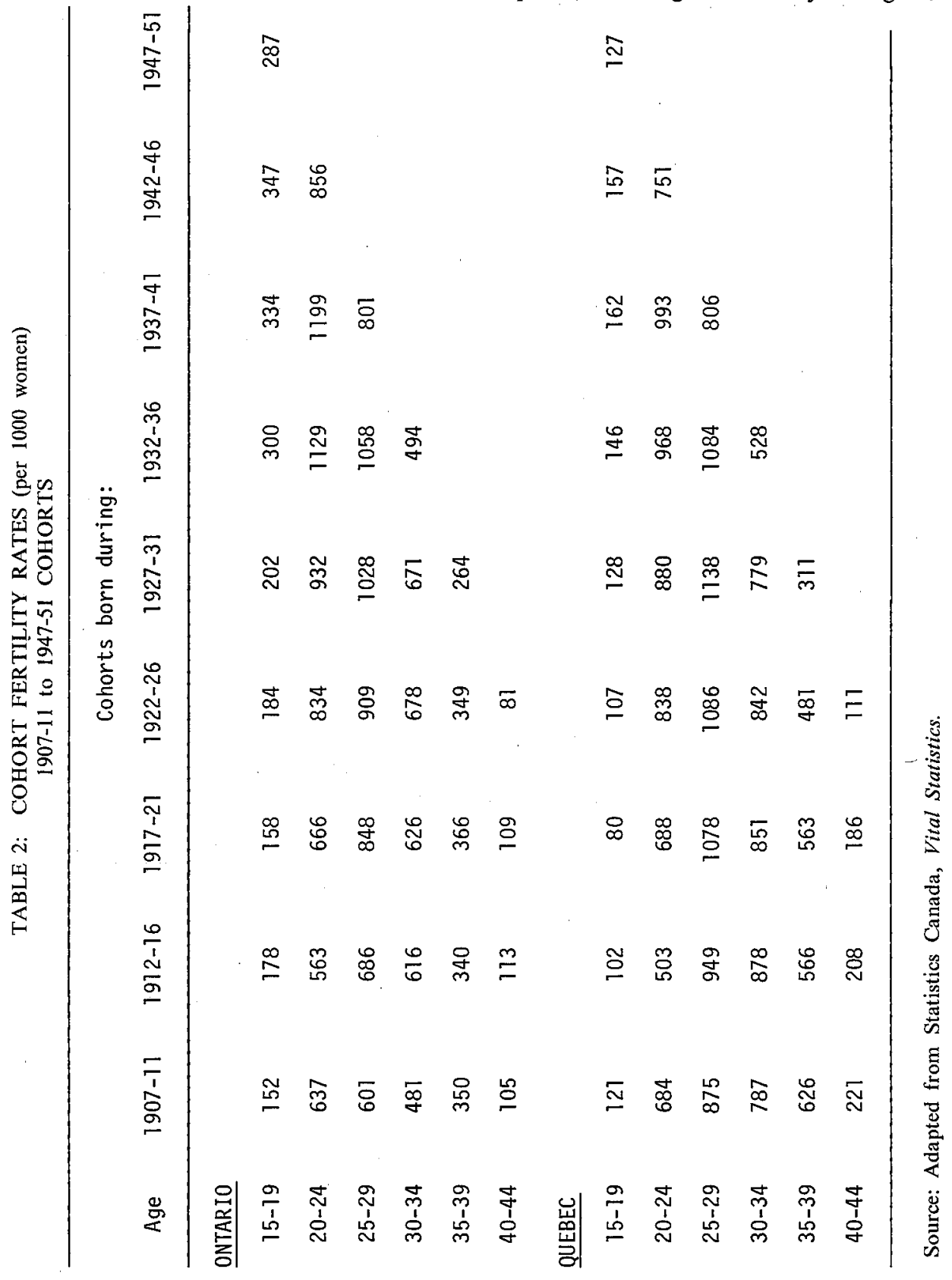




\section{N. Baskara Rao}

Fertility rates of older age groups (30-34, 35-39 and 40-44) generally declined in Quebec with the exception of the 30-34 group among the 1912-16 cohort (Table 2). In Ontario, the decline was confined to the 35-39 and the 40-44 ranges; among women born during 191226 , fertility was on the increase in the 30-44 group. In the younger age groups (15-19, 20-24 and 25-29) fertility was on the increase in both Quebec and Ontario. However, the duration of increase in Ontario was slightly longer in the case of the 15-19 and 25-29 groups. As a result of the economic depression during the early 1930s fertility rates in the 15-19 and 2024 groups declined between 1931 and 1936 in both the provinces. Whenever fertility increased or declined in either province, with a few exceptions, the rate of increase in Quebec was lower and the rate of decline was higher. Earlier it was mentioned that unlike in Quebec, there were instances, in Ontario, of increasing fertility in older age groups. This pattern of change led to a growing convergence in the family sizes of both these provinces.

\section{Family Size}

Completed family size (up to age 44) in Quebec was higher among all the four cohorts: $1907-11,1912-16$. . . and 1922-26; however, the difference gradually narrowed. Among the 1907-11 cohort of women completed family size in Quebec was about $43 \%$ larger and among the 1922-26 cohort, Quebec's family size was only $14 \%$ larger. Significant increase in this province's family size was observed only among 1917-21 cohort (compared to the 191216 cohort). The 1912-16 cohort, compared to the 1907-11, had a smaller family size, whereas the family sizes of the 1917-21 and the 1922-26 cohorts, were more or less the same. In Ontario, on the other hand, cohorts of women born during 1912-16, 1917-21 and 1922-26 had larger family sizes than the preceding ones. The family size of the 1922-26 cohort as compared to $1907-11$ was about $30 \%$ larger in Ontario and only $5 \%$ in Quebec.

\section{Age Pattern of Childbearing}

In both Ontario and Quebec there was a tendency towards early childbearing. The 1922-26 cohort completed a greater proportion of the family size at relatively younger ages in comparison with the early cohorts (Table 3). In Ontario, the 1922-26 cohort completed $86 \%$ of the family size at age 34 against the $80 \%$ of the $1907-11$ cohort at comparable age. In Quebec, at the same age 74\% of the family size was complete among the $1907-11$ cohort and this increased to $83 \%$ among the $1922-26$ cohort. The median age at childbearing (among women aged 15-44) was 28.1 among the 1907-11 cohort in Ontario, and it increased to 28.7 among the 1912-16 cohort and declined to 27.7 among the 1922-26 cohort. In Quebec, the median age increased from 29.9 among the 1907-11 cohort to 30.3 in the succeeding cohort and declined to 28.6 among the 1922-26 cohort. Though Quebec had higher age at childbearing, the decline was faster too, narrowing the differences in age at childbearing.

To sum up, during the period of the "baby boom" (1939-60) there was a substantial increase in fertility in Ontario. In Quebec, on the other hand, the increase was confined to a short period and the post-war increase in fertility, quite prominent in Ontario, was almost negligible. As a result of the differences in the rates of change in fertility, TFR in Quebec which was $58 \%$ higher in 1926 , was $4 \%$ lower in 1965 . Whatever increase in fertility occurred in Quebec was more due to an increasing proportion of people getting married and having children than to an increase in marital fertility. Among women aged 20-29 ASFRs were lower in Quebec in 1965 though they were higher in 1931, while in the 15-19 age group ASFR was lower in Quebec than in 1931 and this gap increased in 1965. Differences between the provinces in ASFR in older age groups and those in ASMFR considerably narrowed over time. In Ontario, women born during 1912-16 and 1922-26 had larger family size (at age 44) compared to the proceeding cohorts. In Quebec, however, an increase in 
TABLE 3: CUMULATIVE COHORT FERTILITY RATES (per 1000 women) 1907-11 TO 1922-26 COHORTS

\begin{tabular}{|c|c|c|c|c|c|c|c|c|c|}
\hline \multirow[b]{2}{*}{ Up to } & \multirow{3}{*}{$\begin{array}{l}\text { age: } \\
\text { ONTARIO }\end{array}$} & \multicolumn{8}{|c|}{ Cohorts born during: } \\
\hline & & \multicolumn{2}{|c|}{$1907-11$} & \multicolumn{2}{|c|}{$1912-16$} & \multicolumn{2}{|c|}{$1917-21$} & \multicolumn{2}{|c|}{$1922-26$} \\
\hline & & Rate & $\%$ & Rate & $\%$ & Rate & $\%$ & Rate & $\%$ \\
\hline 19 & & 152 & 7 & 178 & 7 & 158 & 6 & 184 & 6 \\
\hline 24 & & 789 & 34 & 741 & 30 & 824 & 30 & 1018 & 34 \\
\hline 29 & & 1390 & 60 & 1427 & 57 & 1672 & 60 & 1927 & 63 \\
\hline 34 & & 1871 & 80 & 2043 & 82 & 2298 & 83 & 2605 & 86 \\
\hline 39 & & 2221 & 95 & 2383 & 95 & 2664 & 96 & 2954 & 97 \\
\hline 44 & & 2326 & 100 & 2496 & 100 & 2773 & 100 & 3035 & 100 \\
\hline & QUEBEC & & & & & & & & \\
\hline 19 & & 121 & 4 & 102 & 3 & 80 & 2 & 107 & 3 \\
\hline 24 & & 805 & 24 & 605 & 19 & 768 & 22 & 945 & 27 \\
\hline 29 & & 1680 & 51 & 1554 & 48 & 1846 & 54 & 2031 & 59 \\
\hline 34 & . & 2467 & 74 & 2432 & 76 & 2697 & 78 & 2873 & 83 \\
\hline 39 & & 3093 & 93 & 2998 & 94 & 3260 & 95 & 3354 & 97 \\
\hline 44 & & 3314 & 100 & 3206 & 100 & 3446 & 100 & 3465 & 100 \\
\hline
\end{tabular}

Source: Adapted from Statistics Canada, Vital Statistics reports.

family size could be observed only among the 1917-21 cohort as against the preceding cohort. Quebec continued to have an older age at childbearing; however, the shift towards a younger age at childbearing was far more rapid than in the neighbouring province.

\section{Acknowledgment}

This paper is a part of the author's thesis submitted to the University of Alberta. The author is grateful for the financial assistance received from the University of Alberta for his doctoral research. 
N. Baskara Rao

\section{Selected References}

Henripin, Jacques. 1972. Trends and Factors of Fertility in Canada.

Krótki, K. J. and Evelyne Lapierre. 1970. Fertility in Canada and the Correlates of Religion and Ethnic origin. Translation of the article: la fécondité au Canada, selon la religion, l'oringine ethnique, et l'état matrimonial. Population (Paris) 23:815-834 (1968).

Long, Larry H. 1970. Fertility Patterns among Religious Groups in Canada. Demography 7:135-149.

Rao, Baskara N. 1973. Fertility and Income in Canada: A Time series and Cross section Analysis. Unpublished Ph.D. dissertation. Department of Sociology, University of Alberta, Edmonton.

Statistics Canada. Vital Statistics. Various Reports.

Received September, 1974. 